\title{
COMUNIDADE SURDA: UMA EXPERIÊNCIA DE HUMOR
}

\section{DEAF COMIMUNITY: A HUMOR EXPERIENCE}

Augusto Schallenberger *

\section{Resumo}

A motivação da experiência de ser surdo e o atravessamento das vivências comunitárias e do conhecimento do mundo acadêmico incidem neste estudo como forma de trazer ao leitor uma visão do que é essa diferença de ser surdo em uma sociedade ouvinte e de como nossa comunidade se constitui através de um elo fortíssimo: a nossa língua de sinais, que ultrapassa fronteiras e encontra na literatura de humor um dos aspectos que favorece a constituição da identidade linguística e cultural dos surdos. Procuro debater sobre os conceitos de comunidade pelo viés teórico de Bauman e Miranda. Sobre o humor, pelas lentes teóricas de Bergson, Lévy, Justo e Garbin, entremeando neste texto os discursos culturais surdos com apoio teórico de Lopes e Veiga-Neto, Skliar e Possenti, entre outros. Hoje as tecnologias favorecem o registro das produções surdas, construindo ferramentas para o desenvolvimento cultural na nossa língua nativa e propiciando para as atuais e futuras gerações surdas desenvolvimento linguístico, identitário, cultural e comunitário, fatores fundamentais para uma vida cidadã.

Palavras-chave: Surdez. Língua de sinais. Comunidade surda. Cultura surda.

\section{Introdução}

A experiência visual é algo fundamental na construção dessa diferença, chamada diferença surda. A minha visão entre meus parentes e familiares era pouco estimulada, os meus olhos tinham um trabalho relativamente calmo. Já entre os surdos, o meu sentido de visão se tornou dinâmico, incerto e agitado. Eu não tive paz, não tive mais descanso para meus olhos e a partir daí minha visão sobre meus parentes se tornou, além de intranquila, uma visão que busca um sentido de instabilidade, como se meus olhos que, já acostumados com uma velocidade diferente, conseguissem enxergar as lacunas da maneira de se comunicar dos ouvintes em relação à minha maneira de pensar e comunicar.

\footnotetext{
* Mestre em Educação pela Universidade Federal do Rio Grande do Sul (UFRGS), Porto Alegre, Rio Grande do Sul, Brasil. E-mail: gutschall@gmail.com.
} 
Desde pequeno eu imaginava que teria de enfrentar dificuldades na vida. Sim, foram muitas dificuldades, muitos momentos de conflito, de incertezas. Mas dificuldades todos nós temos e quero dizer, sobretudo, que a dificuldade nunca apareceu sozinha, mas sempre acompanhada de orientações, de estímulo, de carinho.

Sem dúvida, me senti e ainda me sinto muito tocado quando me são contadas as histórias dos surdos que viveram suas infâncias em lares ouvintes e em escolas de ouvintes sem acesso a uma língua para se comunicarem com o mundo. Diferente da calmaria de minha família, onde a comunidade linguística (no caso, alemã) já estava dada, eu como surdo tive que fazer uma busca por uma comunidade e, sempre que se trata de cultura, tive eu também que inventá-la e construir junto aos surdos.

Os surdos com os quais convivo têm no humor uma forma de conhecimento de si e dos outros; através do encontro, seja virtual ou real, os surdos reproduzem características e gestos uns dos outros e dos ouvintes de maneira a criar formas de representação alternativas de nomeação e experimentação. São várias as expressões faciais, os gestos e os contextos onde estes aparecem, mas me parece sempre que o humor surdo tem, além do sentido de descontração, um propósito expressivo que explora as maneiras de ser das pessoas. Essa maneira de representar o outro tem continuidade hoje na internet, com as tecnologias de registro da sinalização dos surdos, algo que não era amplamente acessível há tempos atrás nem aos surdos economicamente mais privilegiados. Utilizar as ferramentas tecnológicas significa focar na produção de registros em língua de sinais, fator de extrema importância dentro dos Estudos Culturais em educação e da Educação de Surdos.

Em comparação com outras formas de expressão utilizadas pelos surdos (desenhos, charges, teatro, mímica, gestos, metáforas), o youtube parece se destacar e ganhar espaço como uma ferramenta que abre outras possibilidades, pois parece abranger diferentes formas de expressão. Sendo um meio de registro inimaginável há tempos atrás por sua agilidade, acredito que traz uma nova maneira de pensar a circulação da língua de sinais, partindo de meio de expressão efêmero e dependente de tecnologias descritivas (e eventualmente filmagem com câmeras), para um registro efetivo e coletivo, semelhante ao modo como as línguas faladas possuem a escrita como apoio para registrar e guardar memórias.

Nesse sentido, acredito que o humor passa a ser a entrada para uma discussão de algo mais amplo que é a literatura surda e o diferencial ocorre justamente por nossa histórica carência 
de registro de nossas produções em língua de sinais. Entre os surdos, ainda são raros os escritores surdos que têm seu trabalho amplamente divulgado. As piadas, crônicas, sátiras e comédias clássicas dos ouvintes estão depositadas em suas memórias, em falas do cotidiano, em livros, em textos diariamente publicados em jornais, em arquivos das redes de televisão, cinema, teatro, internet. Mas se tratando de uma cultura surda, onde estariam depositadas as informações, as memórias, as narrativas, as piadas? Há uma memória coletiva, sem dúvida, há relatos traduzidos para a língua escrita, alguns raros registros na escrita da língua de sinais, outros filmados em VHS ou DVD. O desenvolvimento tecnológico proporcionou formas visuais de registro e isso favoreceu a publicação e divulgação das produções culturais em língua de sinais.

Há metáforas que se repetem conforme situações vividas por surdos, mesmo que esse surdo não tenha acessado conteúdos humorísticos em forma escrita ou gráfica. Entretanto, há uma nova maneira de acessar informações onde as piadas são registradas com eficiência. " $\mathrm{O}$ mundo virtual funciona, então, como depósito de mensagens, contexto dinâmico acessível a todos e memória comunitária coletiva alimentada em tempo real” (LEVY, 1999, p. 64). Esse depósito pode-se dizer que é uma revolução na maneira de registrar qualquer conteúdo e o humor é de grande importância devido ao caráter visual, gestual e expressivo que o humor surdo representa. A partir disso busco revisar dois conceitos que considero importantes para a vida social dos surdos, o de humor e o de comunidade, aliados a minha experiência de sujeito surdo.

\section{Consciência de comunidade}

Procuro debater sobre as noções de humor nas comunidades surdas me referindo ao conceito de comunidade como uma organização fluída do território aparentemente seguro e incontestável da vida comunitária (BAUMAN, 2003). A comunidade é territorial e também temporal, nisso o sentido de rede virtual define uma nova maneira de organizar o encontro, a interação e a comunicação entre os integrantes da comunidade.

É como se houvesse uma transformação no sentido da comunidade surda a partir das mudanças tecnológicas, já que antigamente os surdos dispunham apenas de suas memórias. A comunidade, sob esse novo ponto de vista, não seria um lugar exatamente seguro, mas atravessada pela possibilidade de inventar lugares exteriores que a fizessem existir, como o site youtube, que armazena informações em forma de vídeos, a serem buscadas pelos surdos. Bem, 
poderíamos empilhar corpos em um lugar que parecesse com uma biblioteca, mas acredito ser mais adequado que seja criado um lugar virtual sem cérebros guardados em conservas.

O conceito de humor está direcionado ao entendimento das experiências dessa comunidade. É como se o humor fosse um dos alimentos que mantêm viva a comunidade surda. Os surdos, segundo afirma Ladd (2007), têm uma comunidade não local, mas mundial, já que as línguas de sinais são compartilhadas de maneira mais ou menos acessível aos surdos. A comunidade mundial de que fala Ladd (2007) deve ser vista com cuidado, já que há variáveis diversas que impedem o acesso à internet a uma grande parte dos surdos no mundo. Mas também é possível dizer que as comunidades dos surdos no mundo estão se mantendo em suas especificidades locais, com o auxílio, entre outras coisas, da internet para o registro das sinalizações.

Quando assistem a um vídeo produzido em outro país, os surdos tentam ao máximo compreender o conteúdo em outra língua de sinais, pois não se sentem tão diferentes dos surdos estrangeiros. Os estudos culturais e a pós-modernidade fluída de Bauman (2003) ajudam a pensar uma nova maneira de entender a linguagem, o registro, a consolidação de uma língua, a organização da memória surda através do humor. Esperamos que a fluidez desta pósmodernidade não nos faça perder o sentido de referência quanto às produções da comunidade surda, pois não queremos perder nossos registros, mas resguardá-los do esquecimento.

\section{Experiência surda}

Eu poderia dizer que me tornei surdo em determinado momento de minha vida que foi o momento em que pude compartilhar sentimentos de uma maneira mais clara e mais direta, o momento que passei a aprender língua de sinais. Isso não quer dizer que não havia comunicação nem aprendizado com minha família ouvinte, pelo contrário, posso dizer que fui privilegiado por ter uma família que me estimulou, ajudando-me a crescer. É inegável, porém, que alguns sentimentos tomaram forma quando tive contato com meus pares.

Aprendi os sinais aos 17 anos, quando vim de minha cidade, Montenegro, para Porto Alegre. Desde aquele tempo, ano de 1984, até hoje, vários momentos foram vividos pela comunidade surda, inclusive o questionamento sobre o sentido mesmo da existência de uma comunidade. Percebemos nossa união e os processos de identificação entre nós, decorrentes de nossa experiência singular com a linguagem e a experiência do mundo. No entanto, percebemos 
também que matizes perpassam essas identificações. Alguns desses processos são nada menos do que nossa cultura, língua e comunidade.

Várias transições, no que diz respeito à visibilidade e ao acesso dos surdos à sociedade, também foram vividos por mim. Desde que eu era adolescente, percebi como a inserção dos surdos na escola e nas associações era algo difuso, estranho, parecia que havia conflitos, mas eu não me questionava sobre isso. Fui me inteirar, depois de alguns anos, como integrante da comunidade surda, de que algumas questões ainda não haviam sido explicadas, ainda não estavam claras para que pudéssemos nos apropriar delas. Foram descobertas progressivas, feitas por nós, surdos, na medida em que fomos nos apropriando dos espaços institucionais e políticos, como por exemplo a universidade. Cheguei a ter participação ativa na sociedade dos surdos do Rio Grande do Sul. Gostava dos movimentos da década de 80. Um sentido político nos orientava, nos unia e nos trouxe um sentimento como que familiar.

Depois que me formei no ensino secundário, em 1991, na escola especial Concórdia, voltei para casa de minha família, para trabalhar na empresa de meu pai. Passei a ter pouco contato com a comunidade surda. Somente nos finais de semana eu vinha para Porto Alegre. Minha esposa teve um papel muito importante nesse processo, pois ela estudava na Universidade Luterana do Brasil (ULBRA) e sugeriu que também fizesse faculdade.

Fui para ULBRA, uma universidade que tem um trabalho de inclusão de surdos há mais tempo, e ingressei no curso de pedagogia. O início do curso foi um pouco difícil, pois faltavam intérpretes. Não eram todas as disciplinas que dispunham desse profissional. Depois de algum tempo, a ULBRA passou a disponibilizar o intérprete em todas as disciplinas em que havia surdos matriculados.

Minhas colegas ouvintes da faculdade me perguntavam se eu não deveria usar aparelho auditivo. Eu particularmente não gosto de usar aparelho porque, para mim, é algo incômodo, me sinto mais livre sem ele. Também o aparelho acaba me estimulando auditivamente e, ao contrário do que se pode pensar, isso não surte efeitos positivos, pois a visualidade, que é minha maneira de entender e me relacionar com o mundo, ficam prejudicados quando eu escuto algum som. Alguns surdos gostam do aparelho, isso é algo muito particular, mas para mim é como uma mecanização do próprio corpo, sem qualquer auxílio mais efetivo. Há também os surdos que optam pelo implante coclear, ou são obrigados a isso. Nesses casos, eu sinto que não há 
nada além de sofrimento: os surdos tentando se tornar o que não são, ou seja, ouvintes. Nos estudos eu nunca tive necessidade de usar aparelho, parece que eu consigo muito bem me apoiar na visão, é como se meu olho fosse o meu ouvido. Não ficava incomodado com as perguntas das colegas, somente percebia as diferenças entre o mundo dos surdos e o dos ouvintes.

A minha vivência vai em outra direção. A vivência que eu valorizo com mais intensidade é a sinalizada, que me possibilitou aprender e chegar onde estou. A associação de surdos foi o local onde isso aconteceu, onde encontrei pessoas que me ensinaram a ser surdo. E o humor foi o que permeou toda essa experiência, desde que encontrei outros surdos. O humor é um elemento que perdura na minha vivência com os surdos porque é algo agradável, mostra uma das coisas boas que uma associação de surdos pode proporcionar a seus participantes. A associação dos surdos sempre foi um lugar de socialização, mas nos últimos anos tenho percebido que isso não está acontecendo da mesma maneira. Havia surdos mais idosos que frequentavam e foi com eles que desenvolvi o gosto por uma sinalização mais espontânea e cheia de alusões e sátiras. Eles são figuras conhecidas dentro da comunidade surda, mas foram ficando velhos e também nossa maneira de nos relacionar com a associação mudou.

Parece que há uma urgência do registro do que está sendo sinalizado pelos surdos agora, talvez para que isso possa ser consultado depois e evitar a sensação de vazio que eu mesmo senti em momentos da minha vida em que não conseguia me expressar com meus semelhantes. Como eu disse, as reuniões dos surdos da associação perderam força como movimento unitário e contestador, característica de nossos tempos pós-modernos. No entanto, ganharam força outras dimensões da discussão relativa aos surdos e à língua de sinais, mais visivelmente no âmbito da cultura surda e dos estudos acadêmicos que envolvem os surdos.

Trago uma metáfora que considero pertinente. É como um formigueiro, de onde uma formiga sai em busca de alimento para trazer para casa e alimentar as suas semelhantes. Me sinto como uma espécie de formiga, que saiu em busca de algo e que agora começa a reconhecer os tipos de alimento que são úteis para as formigas. Por que o exemplo de formigas? É que as formigas, apesar de serem insetos pequenos, são muito fortes, sentem o cheiro do alimento a longas distâncias e avisam o que descobriram umas às outras.

Assim como elas, nós também não possuíamos formas acessíveis de comunicação e precisávamos nos comunicar sempre no encontro. Mas hoje há meios de comunicação e de 
registro que nos proporcionam maior mobilidade na sociedade e nos permitem trilhar caminhos cada vez mais diversificados.

Acredito que encontramos formas de expressar aquilo que sentimos, tendo como desafio a utilização dos meios de registro dessa produção cultural. A diferença em relação aos ouvintes é que estes já têm há muito tempo meios de registrar suas formas de expressar, de organizar os pensamentos, seja em papel ou outros materiais. Não que a língua de sinais esteja em desvantagem em relação às línguas orais que optaram pelo registro, mas no meio acadêmico, por exemplo, o registro é um fato incontestável e deve ser respeitado.

Os surdos devem fazer uso da sua segunda língua para que esses registros sejam feitos. Mas porque não o fazer na sua primeira língua, a língua de sinais? O humor é apenas um meio que eu encontrei de mostrar o quanto é plural esta vontade dos surdos de se expressar, o quanto o humor surdo pode ser considerado como produção de expressões dentro de contextos específicos, e como o registro motiva novas visões de comunidade e mesmo de língua.

Os surdos idosos que influenciaram meu aprendizado da língua de sinais eram também pessoas politizadas, que lutavam pelos direitos dos surdos, mas que tinham o humor até como estratégia. Lembro-me das provocações, das piadas, dos jogos em língua de sinais, com os quais eles desafiavam os surdos mais jovens. Isso fez com que houvesse sempre em mim esta dimensão fortemente presente da satirização e do riso, que as pessoas percebem em minha maneira de me expressar. De início, fui oralizado, eu me comunicava somente com pessoas próximas, eu estava numa outra cultura, o que os surdos costumam designar simplesmente com o sinal de "ouvinte". A minha inserção na comunidade surda foi gradual.

De início, eu não conseguia reproduzir as piadas, mas já sentia que havia algum problema, já que aquilo envolvia sentidos que eu não conseguia experimentar. Falo, portanto, do humor como um tipo fundamental de expressão do que é humano. Não simplesmente a piada e o riso, mas esses dois elementos como decorrentes do "[...] acontecimento fundamental e decisivo para a constituição do sujeito" (JUSTO, 2006, p. 104).

\section{Novas formas de comunidade}

O que move o meu interesse por este objeto é o fato de os surdos não possuírem, até o advento de tecnologias mais elaboradas, um arquivo cultural como o que os ouvintes construíram ao longo de tantos séculos de registro escrito. Sendo a escrita um registro 
fortemente ligado à oralidade, penso que a comunicação entre os surdos pela internet é algo fundamental para compreender essa necessidade de um registro.

Aquilo que os ouvintes tiveram na escrita parece ser o que faltava aos surdos até que houvesse a possibilidade de gravar imagens para expressar enunciados em Língua de Sinais. Para os ouvintes, é perceptível a existência de diversos movimentos culturais que, mesmo diante dos "nãos" da sociedade, invadem a escola e desafiam os professores a lidar com linguagens de diversas ordens. Muitas manifestações culturais jovens são criadas nas escolas.

Ao professor cabe explicar os limites e as razões de tantos "nãos”, já que a família, em geral, não dá conta desse papel. Percebo que os ouvintes se reúnem em grupos, ou "tribos", e se relacionam de maneiras diversas em termos de linguagens e gostos. Entre os surdos parece ser mais complicada a entrada em um desses grupos, não por limitações de ordem cognitiva ou social, mas por falta de endereçamento dos artefatos culturais e por causa da língua. No Brasil, a primeira língua dos surdos é a Libras e a segunda é a língua portuguesa, o que não dificultaria aos surdos o uso da rede virtual. E eles realmente utilizam a rede, mas em seus próprios círculos de amizades entre surdos.

Penso que a internet vem sendo explorada pelos surdos de maneira a conseguir uma comunicação mais eficaz, mas destaco que também é uma maneira de produzir e dar significado à cultura, à língua. Sobre a mídia eletrônica, Garbin (2003, p. 121) afirma que essa "se apresenta como um avanço tecnológico capaz de modificar nosso comportamento, com um discurso que se materializa em novas condições de possibilidades, em novos espaços e em novas formas que ele assume".

Os surdos fazem uso desta tecnologia não só objetivando a comunicação, mas também visualizando a sua língua e cultura. Eu mesmo já pensei a respeito da produção de artefatos que façam sentido para mim. Por exemplo, penso muito, hoje em dia, na expressão "ouvi falar", dos ouvintes, e imagino algo semelhante para os surdos. Poderia ser "vi sinais"? Para os ouvintes são maiores as possibilidades de se construir, desde cedo, um arcabouço de sentidos, de representações, a partir das coisas que eles ouvem desde crianças. Para os surdos isso é muito diferente, já que a produção de enunciados em língua de sinais é quase que restrita às comunidades surdas.

Mas o que são enunciados? Enunciados são emissões de sentido em uma língua. O mais importante, porém, mais que os enunciados, as palavras ou os sinais, segundo Possenti (2002, 
p. 133), são os processos de enunciação, onde os sentidos se expressam; "o conceito de enunciação [...] permite compreender melhor sua passagem sobre o efeito de sentido". Como "efeito de sentido" eu posso pensar no que é produzido em mim mesmo, como surdo, ao ver que há a possibilidade de acessar materiais diversos em um site.

Como é a produção cultural dos surdos depois do youtube? Primeiramente não se trata de uma produção cultural linear; não é como antigamente, quando eu aprendia a língua de sinais com os surdos idosos da Associação. Também não é um conteúdo específico a ser aprendido, e ainda não é uma produção idealizada pelas grandes corporações da mídia para distribuir uma cultura surda mais popularizada e vendável. Diferente dos movimentos surdos que vivenciei há alguns anos, parece que uma grande quantidade de informações tem sido exposta aos surdos, possibilitando o surgimento de novas formas de entrar em contato com a cultura surda.

Em termos de memórias dos surdos, como um registro sem materialidade, utilizando apenas imagens que se passavam em narrativas internas às comunidades, pode-se fazer uma comparação. Antes nós tínhamos objetivos aparentemente claros: o clube, a reforma da associação, a verba para a viagem. Agora parece que os objetivos estão mais difusos e não há um conteúdo apenas para ser pensado. São muitas variáveis incluídas, que parecem não caber numa análise. É que as informações são muitas e precisam ser compactadas para que, entre outros enunciados, seja de clara compreensão.

Lévy (1999, p. 53) chama a atenção para "as formas contemporâneas de desmaterialização dos enunciados, que significam o mesmo que escrita e imagem sendo virtualizadas". As informações virtualizadas se misturam mais facilmente umas às outras, pois são mais fáceis de modificar, editar, incluir, compartilhar.

O pensamento tradicional era aliado do sujeito como autor e detentor do sentido de um texto, mas com as novas tecnologias de registro se percebe uma mudança nessa perspectiva. Já não há uma determinação unilateral que parta do sujeito e caminhe no sentido de determinar um objeto de maneira absoluta. As tecnologias mudam as formas de se obter conhecimento e de comunicá-lo. Informações "podem ser compartilhadas entre numerosos indivíduos, e aumentam, portanto, o potencial de inteligência coletiva dos grupos humanos" (LÉVY, 1999, p. 53).

Os surdos têm ocupado a internet desde o seu aparecimento, no início dos anos 90. Desde pequenos fóruns, salas de bate papo, documentações históricas da vida passada das 
comunidades surdas, até hoje em dia, onde quase a totalidade dos programas disponíveis é utilizada pelos surdos. No youtube, muito utilizado, as produções dos surdos estão misturadas, com as produções dos ouvintes. Se um vídeo em ASL ou LIBRAS for muito assistido, aparecerá na página inicial do site, e isso pode significar que os ouvintes também estão assistindo as produções dos surdos.

\section{Comunidade e seus valores}

A questão é: os ouvintes que dominam a língua de sinais fazem parte da comunidade surda? Há diversas respostas para esta questão e a mais comum entre os surdos é que os intérpretes e demais pessoas que dominam a língua de sinais não fariam exatamente parte da comunidade surda. O que acontece é que os surdos muitas vezes julgam que os ouvintes têm a opção de estar ou não participando da comunidade surda, diferente dos surdos, dependentes da comunidade surda se quiserem ter uma vida social mais ampla. Outro caso seriam os ouvintes filhos de pais surdos (CODA) ${ }^{1}$, que são na maioria das vezes considerados como integrantes da comunidade surda, pois adquirem a língua de sinais com seus pais e são considerados como membros da comunidade surda em função do pertencimento cultural e por compartilharem a língua de sinais.

Hoje não posso dizer se estou convencido de que os ouvintes que dominam a Libras são integrantes da comunidade surda, mas posso dizer que há diferentes considerações para que alguém possa se tornar um integrante dessa comunidade. O movimento surdo, com suas lutas, necessidades, convergências ou divergências políticas torna impossível, em alguns meios, distinguir quem é ou não participante da comunidade dos surdos. Um ponto é evidente: não basta ser surdo para pertencer a uma comunidade surda. Há outros aspectos que contribuem

para esse pertencimento cultural, por exemplo, a convergência de aspectos linguísticos (compartilhar uma língua), políticos e sociais, entre outras possibilidades.

Há questões culturais, pragmáticas e históricas, para que os surdos prefiram a sua comunidade composta por pessoas surdas. Entretanto, eu percebo o quanto o sentido de comunidade deve ser explorado para que possam ser compreendidos, desde um foco mais abrangente que não reduza a comunidade à indivíduos rotulados. Procuro ver os sentidos de comunidade, não como um excluindo o outro, mas como um emaranhado de sentidos, 
produzindo novos sentidos, que se cruzam em pontos de apoio, tais como a experiência visual e o uso da língua de sinais. Conforme Lopes e Veiga-Neto (2006, p. 91):

A impossibilidade da tradução do ser surdo é a impossibilidade da tradução universal da identidade surda. Não há uma essência surda, mas há organizações e invenções surdas. Lutar pelo reconhecimento da diferença surda é lutar contra a noção de essência, pois na essência esconde-se aquilo que não podemos manipular, modificar e construir. Acreditar e lutar por uma essência estão na contramão de lutar pela diferença cultural, neste caso, pela diferença cultural surda, que necessita proporcionar condições materiais para a sua existência. Portanto, alguns dos marcadores como lutar pela vida em comunidade, a língua de sinais, são invenções surdas pela manutenção de sua própria existência.

Como Bauman (2003), acredito que a busca por um lugar não é mais desejável nem mesmo plausível nos dias de hoje. O lugar desapareceu, a segurança se dá ironicamente em um meio não seguro, onde nada se segura. A internet é meio virtual que se torna fonte de conhecimento da comunidade e da língua surda. Que engraçado! Hoje em dia buscamos segurança no meio mais inseguro possível.

A cultura visual dos surdos é marcada por uma espécie de intertextualidade, ou seja, a capacidade de transformar textos e imagens em outros textos e em outras imagens, executando em língua de sinais uma espécie de mixagem das experiências da visão. Uma piada em língua de sinais não é apenas uma piada, mas é algo que eu vejo como uma síntese de imagens, estabelecendo relações entre imagens e textos para criar uma mistura de experiências visuais. Na cultura contemporânea, podemos ver essas imagens como o cerne da construção imagética. É como se o sinalizador colocasse a imagem "dentro" da cultura visual dos surdos para aí fazer outra coisa, recriando a imagem com um significado novo.

Um livro pode nos levar a sentir sabores, cheiros, imaginar paisagens com realismo, mas está fortemente ligado à oralidade. As histórias e piadas sinalizadas formalizam algo que os surdos executam no seu cotidiano visual. A literatura é algo importante, mas precisamos pensar que para os surdos a prática da leitura é acompanhada da tradução constante das palavras. Por isso a poética da língua de sinais é muito visível quando o surdo está sinalizando, mas não tanto quando está escrevendo. Seria um tipo de literatura sem o peso histórico do sentido que entendemos na literatura dos ouvintes, pois os surdos não têm uma produção literária. Há milênios que sua cultura, em sinais, passa de geração a geração. 
Para os surdos a metáfora significa pensar de maneira visual algo que na língua oral ou escrita parece ser obscuro. É uma construção que me parece ser mais clara porque dá ao surdo uma noção que pode ser tanto linguística quanto artística a respeito de algo. Não seria, portanto, uma comparação, pois comparação promove a equivalência de características entre dois objetos. Nas metáforas surdas uma imagem pode servir para compreender algo de modo visual. Os surdos as utilizam muito, pois nas conversas elas estão diluídas entre narrações e argumentações, dando o teor de visibilidade àquilo que para os surdos possa parecer abstrato.

Os surdos muitas vezes não entendem as metáforas utilizadas pelos ouvintes, pois suas metáforas são mais específicas. O sentido é passado completamente pela imagem e depende da bagagem e do conhecimento linguísticos de cada um para que possam compree nderas metáforas. Para que a frase se torne mais leve, mais poética, num sentido de comparação entre o que se quer dizer e o que se diz efetivamente, uma metáfora é substituída por outra. Para os surdos, a metáfora é mais que uma figura de linguagem, consistindo em uma maneira de expressar o pensamento, através de imagens que carregam seus próprios sentidos.

Em um grupo de estudos, por exemplo, os surdos solicitam a ajuda dos ouvintes para compreender o significado de alguma metáfora, então os ouvintes, mesmo que limitados na língua de sinais, tentam mostrar visualmente o que significa a metáfora. Os surdos conseguem captar o sentido, pois sua língua é visual, têm os recursos para captar os movimentos e entendêlos adequadamente em sua língua. As emoções, as sensações mais abstratas, tudo aquilo que não se dá facilmente ao entendimento pode ser exteriorizado através das metáforas, através de substituições que tornam o nosso conhecimento indireto, como se não tivéssemos acesso exatamente ao conteúdo do que pensamos. Na verdade, inventamos objetos que possam explicar aquilo que se passa em nossa cabeça. Conforme Pereira (2007, p. 55):

O entendimento indireto toma lugar quando construímos os sentidos mais abstratos de nossa experiência os quais não podem ser compreendidos em seus próprios termos, tais como emoções e atividades mentais e, por esta razão recorrem a outros domínios mais concretos.

As expressões faciais e corporais desempenham também funções linguísticas nas línguas de sinais. Podemos tomar como exemplo a produção surda no vídeo Four Deaf Yorkshiremen $^{2}$ (Quatro Surdos Nova-iorquinos, tradução nossa), em que quatro surdos idosos contam sobre suas infâncias e como passaram por dificuldades, através de um desafio entre 
eles. A disputa consiste em contar uma história que impressione. Um deles aposta que sua história é a mais triste de todas. Os outros vão contando suas experiências com pobrezas e privações na infância, porém todos falavam em famílias surdas com sinalizadores. O último conta a história mais triste: sua família era ouvinte e não sabia sinalizar, então ganha a aposta.

Esse vídeo mostra a importância do aprendizado da língua de sinais na infância, tanto pelo surdo quanto pelos seus familiares. Também revela uma prática comum entre os surdos que é a disputa de quem é mais criativo na narração de uma história.

Os quatro estão tratando de uma questão de representação de uma maneira engraçada, já que a pior história foi a do surdo com uma família ouvinte que não sabia sinalizar. Os surdos consideram a comunicação algo primordial na sua vida, assim como todas as pessoas, mas o diferencial é que os surdos que têm família ouvinte (e a maioria dos surdos tem família ouvinte) podem ser sentir estrangeiros em suas próprias casas. Um surdo que já tenha construído sua identidade surda sente-se, muitas vezes, excluído das conversas familiares, podendo preferir a companhia de amigos surdo, do que dos próprios pais ou irmãos ouvintes.

As piadas podem ser consideradas uma forma de interpretar os acontecimentos. Um humorista tem grande agilidade em associar ideias e dar respostas de maneira imediata. Contar piadas é uma maneira de se relacionar com a linguagem e os fatos. Não são todos que têm facilidade para contar uma piada, isto depende de como a pessoa consegue relacionar o tempo e as palavras. Eu fui muito influenciado por minha família, que gostava de contar piadas. Depois, quando comecei a conviver com os surdos, vi que a forma de organizar o discurso era totalmente diferente.

O riso é um fenômeno interessante entre os surdos. Ocorre geralmente nos encontros, em situações de exploração de sua língua e traços identitários. Essa situação de encontro faz parte da construção da identidade e da afirmação da cultura surda e essa sociabilidade está repleta de traços humorísticos. Segundo Justo $(2006$, p. 110) a “[...] necessidade social e psíquica do humor é tão grande que encontramos, com facilidade, pessoas e certos círculos sociais fortemente impregnados por esta linguagem". A falta de comunicação com os familiares e colegas de trabalho ouvintes parece fazer com que os surdos tenham certo anseio pela comunicação com seus pares, e quando isto ocorre, o prazer do humor parece ser a via mais agradável. 
Não é por acaso que o humor aparece com mais freqüência nos espaços de socialidade, ou que quando ele irrompe nas relações sociais convencionais impõe um corte, normalmente colocando à deriva a interação padronizada pelo instituído (JUSTO, 2006, p. 122).

A palavra socialidade significa um laço social que vai além do instituído no cotidiano, inclusive quebrando ou estabilizando suas normas. Entre os surdos eu percebo a necessidade deste rompimento já que a maioria deles vive entre pessoas que não conhecem sua língua. Mesmo nos momentos de descontração no ambiente de trabalho, é possível que os surdos fiquem excluídos destes processos em que irrompe a linguagem humorística. Por isto a piada em língua de sinais tem um teor de socialização tão acentuado. Possenti (2002, p. 185) observa que "também as piadas precisam estar num discurso para serem piadas, fica inclusive fortalecida a hipótese de que as piadas não produzem discursos novos - eventualmente, nova é a forma, novo é o gênero, mas não o discurso".

\section{O valor da língua de sinais}

A vida dos surdos pode ser comparada ao escalar de uma montanha. Escalada rumo a degraus cada vez mais complexos da sociedade em que vivemos. É certo que alguns surdos não percebiam a importância de alguns significados até que esses fossem traduzidos para a língua de sinais. Os intérpretes não poderiam deixar de ser mencionados. Óbvio, juntos a eles, nós surdos construímos em língua de sinais os conceitos ostensivamente utilizados pelos ouvintes.

Há diversos tipos de intérprete para os muitos níveis de interação dos surdos na sociedade. Há os que sabem o básico da língua para a comunicação com os surdos, podendo nos ajudar em situações simples do dia-a-dia; há intérpretes que traduzem palestras e eventos, o que exige grande fluência e agilidade em colocar o que é falado ou lido em uma construção gramatical adequada ao entendimento dos surdos; e há os intérpretes que efetuam uma tradução mais aprofundada em determinados assuntos ou conceitos, por isso trabalham e convivem com os surdos para conseguir transformar os significados de uma forma mais sistemática.

A entrada de surdos na universidade parece ter trazido mudanças significativas para esta concepção. Alguns intérpretes já estavam com uma formação mais qualificada, mas as coisas para a comunidade surda começaram a ficar estranhas. Ao melhorar as condições de vida de alguns surdos, deslocando o foco das identidades surdas de concepções clínicas para 
concepções socioantropológicas (SKLIAR, 1998) o leque de discussões se abriu. Deixou-se de diferenciar as pessoas por sua linguagem ou seus rituais. Com isso a vida dos surdos pareceu tornar-se mais complexa.

Perceber o mundo agora já não era mais como antes, não tínhamos apenas ouvintes poderosos para nos dizer o que fazer e muitas coisas nos foram trazidas. Não temos apenas bocas que se movimentam estranhamente. Nós compreendemos algumas coisas do "mundo acadêmico", mas não tudo. Aliás, a maior parte parece estar ainda distante de nós.

Falar em um "mundo acadêmico" não é algo genérico, assim como também falar em um "mundo surdo". Segundo Miranda (2001, p.25), "O mundo surdo como a produção de significados ou de expressão dos surdos" é efetivamente um modo de conceber o mundo. Aquilo que tem sentido para nós surdos não tem sentido, necessariamente, para os ouvintes, percebo isto claramente através do humor, onde os surdos acham graça de algumas coisas que os ouvintes não compreendem e vice-versa.

Quando um intérprete constrói uma frase em Libras ele transmite, a partir de sua experiência ouvinte da linguagem, a sua língua oral e seu papel de mediador. Se formos pensar naquilo que efetivamente nos é transmitido através dos intérpretes, vemos a contingência histórica e cultural que seleciona, em dados momentos, o que será ou não traduzido, dependendo do espaço que os surdos ocupam, o ambiente em que atuam.

Ainda há os surdos que compreendem melhor o português e podem decodificar os significados através da leitura, e por si só estabelecer significados. Quando o surdo que lê bem consegue se expressar na lógica visual e gestual dos surdos, pode tornar determinada palavra relevante para outros surdos.

O mundo surdo certamente não é separado do mundo ouvinte. Vivemos, no entanto, no mesmo mundo, mas tanto na vida social como na acadêmica, não temos as mesmas condições que os ouvintes de acessibilidade aos conceitos. E adquirir conceitos não deve ser como comprar produtos. No mundo surdo há regras e valores estabelecidos entre aqueles que conhecem a língua de sinais e a utilizam. As festas e reuniões, movimentos políticos e eventos artísticos fazem parte do mundo surdo. Além disso, há o indizível, que é parte fundamental da cultura surda e por questões de limitação linguística continua num lugar intraduzível. 


\section{Sujeitos culturais e comunidades}

Alguns surdos partem para a cidade grande, ou outras regiões que lhe ofereçam mais oportunidades. Em busca de trabalho, educação e contato com outros surdos, saímos de nossas cidades de origem para ter uma vida em comunidade nos grandes centros urbanos. Em relação ao lugar da comunidade surda, o surdo Wilson Miranda (2001, p. 28) afirma que:

\footnotetext{
Em alguns dos grandes centros os discursos são de hegemonia ouvinte e, geralmente, os surdos são oralizados e o movimento se apresenta menos intenso. Se a predominância nos discursos é a cultura surda, então predomina a força surda construída a partir dessa cultura. Essa mudança de discurso possibilita o que denominamos de sujeito cultural.
}

Portanto, para nos tornarmos sujeitos culturais, como afirma o surdo Wilson Miranda, temos de nos deslocar espacialmente, nos readaptarmos em termos de discursos e conquistar uma consciência de coisas que permanecem obscuras, devido às diferenças linguísticas. Temos uma comunidade, isso não pode ser negado. Os movimentos migratórios e as transgressões políticas, culturais e epistemológicas provam isso. Eu, por exemplo, saí de minha cidade, de uma rotina de vida no interior e não via a possibilidade de outro mundo existir. Quando me mudei para Porto Alegre, com o meu encontro com os surdos, aprendi muito em termos linguísticos e isso me possibilitou aprender coisas novas.

Quando os surdos passam a frequentar a universidade, ganham um status diferente. Um surdo que tem a possibilidade de fazer mestrado e doutorado pode defender sua comunidade e promover modelos mais flexíveis de usos da língua. Tudo isto contribui de maneiras diversas para o movimento político, para as concepções que nós, surdos, temos do mundo, e para as concepções que os ouvintes têm de nós. Eu vejo que as universidades no Brasil têm ampliado seu trabalho junto às comunidades surdas e essas comunidades têm se desenvolvido em função desse "mundo acadêmico".

Daí a importância da internet como um veículo que promove uma política mais global de interação e troca de informações entre surdos e ouvintes. Em termos de concepção e construção de subjetividade dos surdos, a internet trouxe muitas mudanças significativas, pois permitiu que os surdos se comunicassem com pessoas surdas de diferentes países. Os surdos percebem que as comunidades surdas em outras partes do mundo se organizam de diferentes formas e têm soluções diferentes para problemas parecidos aos nossos. Além disso, os artefatos 
culturais surdos são mais divulgados. Esse é o caso do humor, que através da comunicação gestual pode ser entendido em diferentes línguas de sinais.

Parece-me que as associações ainda buscam uma unidade, uma comunidade única e poderosa que vá mostrar a capacidade dos surdos em desempenhar as mesmas funções que os ouvintes. No entanto, vejo que esta união integral dos surdos não é possível, e talvez nem seja desejável. As associações lutaram, e ainda lutam, por integração e pela imagem do surdo como alguém capaz. As culturas surdas, no entanto, vêm se mostrando cada vez mais locais e sutis. Na publicidade, ou no uso de uma ferramenta como youtube, o que vejo é a possibilidade de trocas entre produções culturais.

Os surdos parecem estar atualizando a sua relação com a rede, paulatinamente, dando cada vez mais vazão às suas maneiras de ver e sentir o mundo, utilizando para isto as possibilidades do mundo virtual. Os surdos adultos utilizam a rede tanto quanto os jovens, pois ali veem a possibilidade de consolidar sua cultura e se aproximar de surdos que estão em países distantes.

Em relação ao consumo da cultura, os surdos têm tido visibilidade em alguns espaços da mídia, com alguns comerciais mostrando a língua de sinais. No entanto, essa maneira de “descobrir” os surdos está ligada a interesses capitalistas. Contudo, ao perceber as experiências dos surdos, um ouvinte poderia compreender as nossas dificuldades. Algumas situações, porém, nos fazem pensar que somente se o ouvinte aprender a língua de sinais conseguirá entender. As comunidades surdas passam a ocupar outro lugar. $\mathrm{O}$ que antes era apenas uma questão de visibilidade na imagem de alguém "diferente", sendo mostrado na televisão, agora parece envolver os não entendimentos e as disparidades entre as experiências do mundo dos surdos e dos ouvintes.

Uma comunidade surda pode ser um local de difícil acesso, pois para estar em uma comunidade surda é necessário entender suas implicações. Mas o que significa uma "comunidade"? Haveria muitas comunidades dentro da comunidade surda? Acredito que os surdos devem buscar outras referências fora de seus locais comunitários, para que a cultura surda se fortaleça, criando diferentes estratégias de vida. Uma comunidade não se restringe a membros com interesses iguais. Cada membro da comunidade tem seus próprios pensamentos e, por isso, os interesses são diferentes. Um grupo como o dos surdos também guarda suas diferenças internas, que provém do contexto de cada comunidade e das diferenças individuais. 
Há diferenças entre os surdos: surdos acadêmicos, surdos sem escolaridade, surdos ricos, surdos pobres, surdos cegos, surdos deficientes, surdos negros, mulheres surdas, surdos LGBT. Todos esses grupos serão categorizados a princípio pela designação “surdos”? Ou seriam eles designados pelos seus respectivos subgrupos a que pertencem? Esta questão parece insolúvel, seria preciso perguntar a cada um como gostaria de ser denominado.

\begin{abstract}
As diferenças não derivam dos atributos da minoria em questão, e ainda menos de qualquer estratégia que os membros da minoria possam assumir. As diferenças derivam do contexto social em que se constituíram como tais: dos limites. A natureza daquela atribuição forçada que levou a imposição de limites. A natureza de "sociedade maior” deixar sua marca indelével em cada uma de suas partes (BAUMAN, 2003, p. 83).
\end{abstract}

As comunidades surdas também se constituem a partir das diferenças socialmente construídas. A maior parte dos surdos não percebe que é surdo, não adquire uma identidade surda, não questiona sobre esse modo de viver que seria diferente do modo de vida de alguém que ouve. Uma comunidade surda, com todas as suas diferenças internas, evidencia um estatuto minimamente sólido para que se possa fazer um estudo.

O tipo de relação que as pessoas estabelecem, como o pensar e o fazer, o expressar, através deste domínio da rede mundial de computadores é algo realmente novo. $\mathrm{O}$ fato de as pessoas terem coragem de postar suas opiniões em língua de sinais significa que uma expressão linguística, a dos surdos, poderá ser acessada.

Em sua multiplicação de ferramentas, a rede questiona o pensar e traz "novos estilos de raciocínio e de conhecimento, tais como a simulação, verdadeira industrialização da experiência" (LÉVY, 1999, p. 157), e parece trazer, com a possibilidade de veiculação da imagem em movimento, um novo meio de comunicação e informação. Esse meio talvez não seja tão confiável como as instituições modernas que detinham o saber, mas é certamente uma nova maneira de fazer o surdo entrar no jogo do saber e do poder ${ }^{3}$.

Há inúmeras comunidades surdas na internet. No youtube encontramos diferentes formas de expressão, diferentes línguas de sinais, diferentes assuntos quanto à questão da surdez. No entanto, o que mais tem despertado o meu interesse é a questão do humor em língua de sinais, um elemento da cultura surda.

Do mesmo modo que as nações promulgaram a necessidade de uma identidade, os surdos, como comunidade, também se referem às suas representações. No entanto a "promessa 
de assimilação pode ser desfeita a qualquer momento sem que qualquer razão seja apresentada" (BAUMAN, 2003, p.86), e isso não quer dizer que os surdos estejam em busca de uma afirmação irrecusável de sua identidade.

É longa nossa tradição de pertencimento e dispersão. Nós, surdos, estamos na corrente de uma tradição de divisões dos seres humanos, apesar de nem sempre termos participado das deliberações de maneira ativa. As escritas sobre os surdos são, em sua maioria, escritas de ouvintes sobre surdos, o que nos faz uma espécie de povo pós-moderno, não por sermos construídos pelos discursos ouvintes, mas por termos nossa cultura visual apartada da centralidade da palavra escrita. Uma cultura que entra no jogo do saber/poder por causa de reivindicações de um grupo social e mostra uma divisão efetuada nos primórdios das civilizações. Nesse momento, entendo o humor, tendo como base a afirmação de Justo (2006, p. 122) de que "o humor é um poderoso instrumento de produção de linguagem e socialidade". Talvez após os lamentos por nossas histórias de sofrimento, seja hora de alargar o registro de nossa presença no mundo com uma dose de humor.

O que Bauman (2003) aponta como dependência em relação às culturas centrais e que rege as polarizações das minorias étnicas pode ser verificado nas comunidades surdas a partir das legislações sobre as línguas de sinais e da divulgação das culturas surdas. No entanto, é como se a diferença surda ainda estivesse profundamente relacionada com aquilo que os surdos não possuem, aquilo que lhes falta. Bauman (2003, p. 83) afirma que a minoria étnica “[...] é uma rubrica sob a qual se escondem ou são escondidas entidades sociais de tipos diferentes, e o que as faz diferentes raramente é explicitado”. Portanto, Bauman (2003) não olha essa divisão a partir da luta, mas a partir da definição de lugares e de diferenças.

Concordo com o sociólogo, pois essas divisões ainda detêm a maioria das possibilidades de vida dos surdos. Por exemplo, se não souber ler, estarei excluído de muitos espaços da sociedade. Há uma rigidez em não explicar as variações. Mesmo quando falamos em "várias culturas" ou empregamos o "multi" querendo abarcar a todos, estamos fazendo uma generalização ao gosto das culturas centrais, que admitem a existência de grupos diferentes, com a condição de que possam ser nomeados, de maneira inteligível, pelas culturas centrais.

Apesar da dureza destas divisões binárias como: maioria/minoria, surdos/ouvintes, existem maneiras de questionar essas divisões, fazendo com que a vida se manifeste com força. O risível faz essa quebra. O que Bergson (2001) coloca como o mecânico sobreposto ao vivo é 
de certa maneira o que vivemos quando nos forçamos a imitar um modelo. Entender a diferença local é desde já vê-la num panorama de regras e subversões históricas que ultrapassam a constituição de uma identidade ou comunidade. São questões históricas do ponto de vista de implementação das vozes que contam esta história, as vozes que sofreram tal história e ao mesmo tempo são capazes de narrar esta história. Se o humor é uma via possível, isso se deve à diferença, materializada em uma luta que perdura na busca de uma via alternativa às imposições ouvintes, no entanto, também há uma dimensão que interessa somente aos surdos e aos que compartilham de sua maneira de se expressar.

Virtualidade é uma característica da cultura contemporânea que coloca os indivíduos em conexão, que disponibiliza o saber e otimiza o tempo que despenderíamos numa busca em uma biblioteca, ou uma pesquisa por histórias humorísticas, por exemplo. O mundo virtual é um espaço que vem possibilitando aos surdos de diferentes partes do mundo se contatarem e descobrirem as características de diversos outros países. As piadas são um tipo de história que colocam diferentes culturas surdas em contato muito próximo, pois são contadas utilizando os recursos das línguas de sinais, tal como gestos e expressões faciais, o que facilita a comunicação entre surdos de países muito distantes. Segundo Lévy (1999, p.70) “A 'realidade virtual', no sentido mais forte do termo, especifica um tipo particular de simulação interativa, na qual o explorador tem a sensação física de estar imerso na situação definida por um campo de dados".

Quando um surdo assiste ao vídeo de um surdo de outra parte do mundo, está também sendo tocado, sendo provocado e estimulado a dar continuidade às histórias, é uma arte em rede. A "rede" algo que não tem consistência física, mas acaba se efetuando no mundo físico através das manifestações culturais dos surdos.

\section{Comunidade de humor}

O humor é uma verdade. E há uma verdade? Segundo Platão o riso é uma afecção não digna de preocupação, não passando de um estímulo corporal baixo que engana a verdade do ser. Mas a verdade dos surdos está no corpo mesmo, nas sensações classificadas como "falsas" por Platão. E é neste domínio que nós, surdos, registramos a possibilidade de procurar nossas verdades (ALBERTI, 2002). Essas verdades não devem ser definitivas nem absolutas, já que o humor é exatamente aquilo que irá desfazer a seriedade de uma verdade. 
Então, de um lado temos a verdade das mãos que procuram pensar o mundo através de seus movimentos e, de outro, temos a exclusão do corpo segundo a filosofia platônica. Trata-se de um paradoxo que não é exatamente minha preocupação, nem parece ter sido a de outros surdos, mas é interessante que daí tenhamos um deslocamento da questão da experiência do surdo.

As festas dos surdos são sempre uma oportunidade deles se encontrarem com seus pares, as pessoas que entendem sua língua e a forma pela qual organizam os seus pensamentos. Há, por vezes, uma exaltação da festa surda, considerada o momento crucial de construção e perpetuação de uma identidade. Entendo esse momento não somente como uma exaltação do riso e do prazer, mas como possibilidade de encontro entre as pessoas que compõem uma comunidade linguística.

Um amigo me contou uma história, a título de anedota que expressa um conflito cultural bastante interessante. Sabemos que o ex-presidente Lula não tem um dos dedos mínimos. Bem, conta um dos surdos com quem conversei sobre este trabalho, que o presidente teve um encontro com militâncias surdas no palácio do planalto e que os recebeu de braços abertos. Um dos líderes lhe ensinou o sinal de "eu te amo", nosso tradicional I, L Y (retirado das iniciais da expressão em inglês I Love You), que se disseminou entre muito artistas ouvintes. Mesmo sem o dedo mínimo, o presidente fez o sinal e cumprimentou os surdos, no entanto, quando foi colocar a mão no peito sinalizando o quanto lhe agradava a presença dos surdos, sem querer acabou chamando os surdos de "feios" (já que o "L" à altura do peito tem esse significado).

As piadas dos surdos são, em sua maioria, relacionadas às suas experiências de encontro com o um ouvinte. São histórias que refletem o conflito do encontro entre culturas, por isto são histórias despretensiosas, quanto ao caráter estritamente político das situações de embate social, que refletem uma gama de impossibilidades vividas pelos surdos. Isto marca o que seria uma das figuras, ou imagens às quais os surdos frequentemente retornam que é a imposição das experiências auditivas em detrimento de experiências visuais. Reichert (2006, p. 22) observa que:

Ser interpelado pela experiência significa vivê-la de muitas formas, pois ela faz diferença e deixa marcas profundas em quem a vive. Uma experiência é como poder entender o que se está vendo, sem a dependência de outra pessoa significa para nós surdos não só autonomia, mas a possibilidade de dignidade. 
Além da autonomia que os surdos desejam, existe também o caráter da experiência válida para ouvintes e surdos, que é o que culturalmente se instaura nos dias de hoje. As mídias são de uso comum para surdos e ouvintes, mas os surdos são por elas interpelados de maneira diversa, através da linguagem visual, o que faz com que reivindiquem mais maneiras de acessar os conteúdos midiáticos. Posso ver essa interpelação também a partir da linguagem humorística, que certamente é de uso comum entre todos, no entanto o que mais se vê, ao menos nas produções das mídias brasileiras, são conteúdos de difícil acesso aos surdos. O que faz falta é uma maneira de condensar a visualidade e os conteúdos humorísticos comuns, para que os surdos se sintam contemplados.

As vivências dos surdos, que estão contidas nas piadas, mostram a possibilidade de se fazer brincadeiras com coisas que nos afetam. Há um tom de crueldade nas histórias, no sentido de que o surdo estaria à mercê de uma queda onipresente ou sofrendo as consequências de sua diferença. Há uma história engraçada, de autor desconhecido, que é muito popular entre os surdos: os deficientes foram convocados por Deus para subirem o monte dos milagres, para que suas deficiências fossem curadas. O primeiro a subir foi o cego que com sua muleta subiu vagarosamente o morro. Ao chegar lá, Deus falou: "Meu filho, abra os olhos e vê!”. O cego abriu os olhos e enxergou! Imediatamente jogou sua muleta morro abaixo. Logo em seguida subiu o cadeirante, que com dificuldade chegou ao topo do morro. Deus lhe disse: "Meu filho, levanta e anda!" Imediatamente o cadeirante ficou sobre os dois pés, atirou a cadeira morro abaixo e saiu correndo. O terceiro a subir foi o surdo, que, acompanhado de um intérprete para entender o que lhe diria Deus, subiu o morro. Deus lhe falou: "Meu filho, abre os ouvidos e ouve!". Dito isto, o surdo passou a ouvir e prontamente atirou o intérprete de cima do morro.

Essa piada mostra uma situação imaginária que reflete uma vivência comum dos surdos: a companhia de intérpretes em momentos de comunicação. Um momento de comunicação com a divindade seria muito mais proveitosa se fosse direta. Imaginemos a situação de um surdo contando esta ou outra piada a uma pessoa ouvinte, este ouvinte não sabendo a língua de sinais solicita a tradução de um intérprete. Acho que alguns ouvintes não compreenderiam o quanto esta história é engraçada para os surdos. Isto é algo que acontece com quase todas as nossas piadas. Elas não são compreendidas pelos ouvintes, assim como nós temos dificuldade em compreender as piadas ouvintes. 
Os surdos até então depositavam o saber e a intelectualidade nas mãos dos ouvintes, agora têm a possibilidade de, eles mesmos, se tornarem intelectuais. Vejo neste tipo de produção, de histórias e piadas, uma produção também da ordem do saber, pois está vinculada a uma série de atitudes novas frente à linguagem.

\section{Considerações finais}

Os humoristas surdos produtores de vídeos, que mostram a cultura surda em seus conflitos internos, têm a possibilidade de se encontrar no espaço virtual, de trocar ideias e experiências sobre seus diferentes contextos políticos e sociais. Dessa forma se pode consolidar uma rede mundial de surdos, com trocas não apenas de informações, mas também de expressões em ato, ou seja, com as histórias dos surdos sendo contadas como uma produção ativa da cultura.

A produção em língua de sinais na internet é muito vasta. Produzir um vídeo é relativamente fácil, bastando dispor de uma câmera, ou mesmo uma webcam, e um programa de edição como o MovieMaker, do Windows. Isso mostra uma forma muito mais acessível e capaz de despertar o interesse dos surdos em registrar suas narrativas. Produzir humor, poesia ou quem sabe, futuramente, romances em línguas de sinais é algo que parece estar guardado como uma possibilidade entre os surdos.

Quanto à expressividade no humor: com o uso de metáforas, expressões faciais e corporais, observo que essa é uma forma de contar histórias, considerando a construção linguística e visualmente expressiva na língua, com o objetivo de trazer imagens que possam ter um efeito estético. Os surdos as utilizam muito, pois nas conversas elas estão diluídas entre narrações e argumentações, dando o teor de visibilidade àquilo que possa parecer abstrato. Acredito que a chamada "alfabetização digital" (BURGEES; GREEN, 2009), tem consequências na maneira como se aprende e como se entra em contato com a cultura. De acordo com Burgees e Green (2009, p. 200), "as escolas, ao menos as escolas australianas, controlam o conteúdo acessado pelos alunos, inclusive proibindo o acesso ao youtube". Acredito que as escolas brasileiras, com suas exceções, não se afastam muito dessa realidade, já que as aulas de informática são geralmente direcionadas ao conteúdo das disciplinas.

As tecnologias digitais, em especial programas de armazenamento como o youtube, podem favorecer uma inserção pedagógica e cultural mais ampla do que os conteúdos escolares. 
É possível que a cultura, através de artefatos visuais, possa se consolidar de forma mais efetiva para surdos que somente entram em contato com a língua de sinais no ambiente escolar.

Por fim, acredito que não é um sonho distante pretender que os surdos tenham êxito na comunicação, na expressão de sua cultura e no uso do espaço escolar para entrar em contato com sua identidade. Os professores podem propor novos usos da tecnologia, mesmo com recursos escassos. Um professor em sala de aula pode até mesmo usar seu celular para gravar as produções dos alunos. Tudo depende da criatividade e da vontade dos educadores. Registrar a cultura surda é preservar a própria existência dos surdos.

\begin{abstract}
The motivation of the experience of being deaf and the crossing of the community experiences and the knowledge of the academic world take place in this essay as a way to bring to the reader a vision of what is this difference of being deaf in a hearing society and of how our community is constituted through a very strong bond - our sign language, which crosses borders and finds in humor literature one of the aspects that favors the constitution of the linguistic and cultural identity of the deaf. I try to discuss the concepts of community through the theoretical lens of Bauman and Miranda. About humor through the theoretical lenses of Bergson, Lévy, Justo and Garbin, adding to this text the deaf cultural discourses with the theoretical support of Lopes and Veiga-Neto, Skliar and Possenti, among others. Nowadays, technologies favor the recording of deaf productions by building tools for cultural development in our native language, providing for current and future deaf generations linguistic, identity, cultural and community development, fundamental factors for a citizen's life.
\end{abstract}

Keywords: Deafness. Sign language. Deaf community. Deaf culture.

\title{
Referências
}

ALBERTI, V. O Riso e o Risível: na história do pensamento. Rio de Janeiro: Jorge Zahar, 2002.

BAUMAN, Z. Comunidade: a busca por segurança no mundo atual. Rio de Janeiro: Jorge Zahar, 2003.

BERGSON, H. O Riso. São Paulo: Martins Fontes, 2001.

BURGEES; J.; GREEN, J. Youtube e a Revolução Digital. São Paulo: Aleph, 2009. 
GARBIN, E. M. Cultur@s Juvenis, Identid@des e Internet: questões atuais. Revista Brasileira de Educação, Belo Horizonte, v. 23, p. 119-135, 2003. Disponível em: <http://www.scielo.br/pdf/rbedu/n23/n23a08.pdf >. Acesso em: 06 mai. 2019.

JUSTO, J. S. Humor, educação e Pós-Modernidade. In: ARANTES, Valéria Amorim (Org.). Humor e Alegria na Educação. São Paulo: Summus, 2006. p. 103-126.

LÉVY, P. Cibercultura. São Paulo, Ed 34, 1999.

LOPES, M. C.; VEIGA-NETO, A. Marcadores Culturais Surdos: quando eles se constituem no espaço escolar. Perspectiva: Revista do Centro de Ciências da Educação, Florianópolis, v. 24, NESP, p. 81-100, jul./dez. 2006. Disponível em:

<https://periodicos.ufsc.br/index.php/perspectiva/article/view/10541/10078>. Acesso em: 06 mai. 2019.

MIRANDA, W. de O. Comunidades dos Surdos: olhares sobre os contatos culturais. Porto Alegre, 2001. Dissertação (Mestrado em Educação) - Programa de Pós-Graduação em Educação, Faculdade de Educação, Universidade Federal do Rio Grande do Sul, Porto Alegre, 2001.

PEREIRA, P. F. Psicanálise e Surdez: metáfora conceituais da subjetividade em Libras. Curitiba, 2007. Dissertação (Mestrado em Educação) - Curso de Pós-Graduação em Letras, Universidade Federal do Paraná, Curitiba, 2007. Disponível em:

<https://acervodigital.ufpr.br/handle/1884/11336>. Acesso em: 06 mai. 2019.

POSSENTI, S. Os Limites do Discurso. Curitiba: Criar, 2002.

REICHERT, A. Mídia Televisiva sem Som. Porto Alegre, 2006. Dissertação (Mestrado em Educação) - Programa de Pós-Graduação em Educação, Faculdade de Educação, Universidade Federal do Rio Grande do Sul, Porto Alegre, 2006. Disponível em: <https://lume.ufrgs.br/handle/10183/10016>. Acesso em: 06 mai. 2019

SKLIAR, C. (Org). A Surdez: um olhar sobre as diferenças. Porto Alegre: Mediação, 1998.

\footnotetext{
Notas

${ }^{1}$ https://culturasurda.net/2013/02/01/coda/

$2 \mathrm{https}: / /$ www.youtube.com/watch?v=2upAsFzO9AU

${ }^{3} \mathrm{Na}$ história do ocidente, os surdos tiveram poucas oportunidades de expressar sua opinião e sua vontade. A partir do momento que os surdos podem responder às exigências do capital, do mercado, da ciência, mesmo que sejam por eles dominados, calados e limitados, podem ao menos estar frente a frente com o colonizador. É um capital que está sendo desvendado, um capital oral. Os surdos rastejam como cobras pela tecnologia e descobrem suas possibilidades, cada um dos nossos braços é uma serpente atrás de sua presa.
} 
Submetido em 30 de agosto de 2019

Aceito em 05 de novembro de 2019

Publicado em 02 de dezembro de 2019 